\title{
Strength Performance of Hevea Brasiliensis at Structural Size
}

\author{
Nur Emilia Azira bt Kamisly ${ }^{1}$ and Gaddafi bin Ismaili ${ }^{2}$ \\ Civil Engineering Department, Faculty of Engineering, Universiti Malaysia Sarawak, Kota Samarahan, Malaysia ${ }^{1,2}$
}

\begin{abstract}
Demand for wood as structural components has kept increasing. The alternatives available to maintain an adequate supply include the controls to regulate the annual falling rate or to find fast-growing plantation trees as replacements for traditional popular species. Thus, this study focuses on the determination of strength performance of Hevea Brasiliensis at a structural size in green and air-dry condition. The British Standard BS 5820: 1979 method of testing structural size timber was adopted to test the strength properties of this species. For this thesis, the mechanical properties of Hevea brasiliensis that will be discussed is the modulus of elasticity (MOE) in NDT test. The physical properties that affect the strength of timber related to this study are moisture content and basic density. It was found that the strength value of modulus of elasticity was high in air-dry condition with an overall mean value of $14237.03 \mathrm{~N} / \mathrm{mm}^{2}$ compared to Hevea brasiliensis in green condition with MOE value of $14208.21 \mathrm{~N} / \mathrm{mm}^{2}$. The average density in green condition for top and bottom part of Hevea brasiliensis are $795.60 \mathrm{~kg} / \mathrm{m}^{3}$ and $825.70 \mathrm{~kg} / \mathrm{m}^{3}$. While, the average density in air-dried condition for top and bottom part of this timber species are $659.10 \mathrm{~kg} / \mathrm{m}^{3}$ and $756.60 \mathrm{~kg} / \mathrm{m}^{3}$ respectively. For samples in green condition, the moisture content is $55.02 \%$ for the top part and $55.41 \%$ for the bottom part, while samples for the air-dry condition is dried until moisture content reached $18 \%$. At air-dry condition, Hevea brasiliensis classified under light hardwood. This study revealed that the strength properties of Hevea brasiliensis in airdry condition are higher than in green condition. Also, the density was higher at bottom part compared to the top part of this species.
\end{abstract}

Keywords: modulus of elasticity, basic density and moisture content.

\section{INTRODUCTION}

The rubber tree or Hevea Brasiliensis which is native to Brazil is widely planted for the production of latex in South-East Asia, mainly in Indonesia, Malaysia and Thailand. Between 25 to 30 years of age, the production of latex is uneconomical, thus the trees are fell for replanting [6]. Previously, the felled trees were of low commercial value and were mainly used as fuelwood. In the late 1970 's, the intensive commercial utilization of rubberwood started in Malaysia, but since the mid 1980s rubberwood is one of the most popular timbers for making furniture and other wood based products [6]. About $46 \%$ of the world's rubber is produced in Malaysia. The greatest rubber plantation in Malaysia is in Johare State of Southern Malaysia where rubber cultivation occupies about 42 million acres or about $65 \%$ of the total cultivated is in the country [20]. Nowadays, rubberwood becomes one of the important resources for the Malaysian timber industry and can become one of the major money earners for this industry. Therefore, a study on strength performance of Hevea Brasiliensis at a structural size is conducted to know more about the application of this fast-growing species.

\section{METHODOLOGY}

A. Materials and Sampling Methods

A total of 20 Hevea brasiliensis trees with ages ranged from 50 to 55 years were collected from rubber plantation located in Gedung, Serian. Figure 1 below shows the sawing process for obtaining the tree sample for this study. Samples' trees were cut 0.3 meters from ground level for the planted tree and 1.2 meters from the ground level for

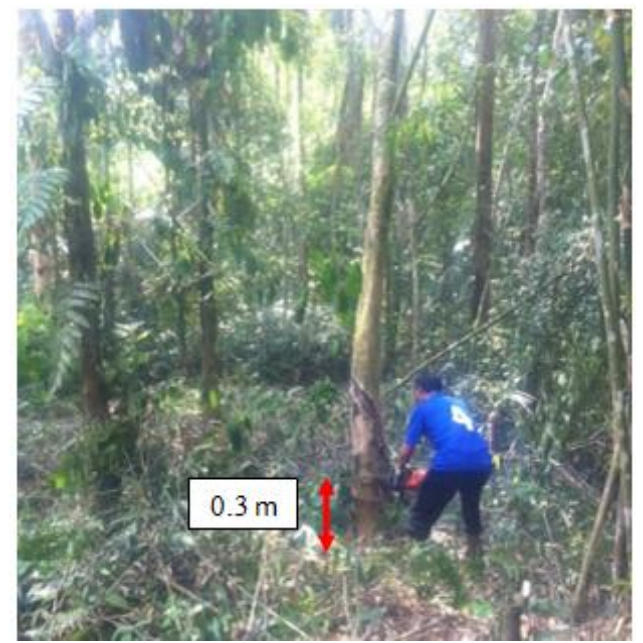

Fig1.Sawing of tree sample at 0.3 meters from ground level

to the wild tree by using a chainsaw. Selection of trees carried out for the samples were done by measuring the diameter of the trees ranged from $240 \mathrm{~mm}$ to $340 \mathrm{~mm}$ by using measuring tape at breadth height. All the tree samples possessed the common characteristics such as healthy, with straight bole and having the minimum diameter of $240 \mathrm{~mm}$. The felled trees were sawn to $\operatorname{logs}$ form with length 2.5 meters for both the upper and bottom part of the trees. Both part of this tree trunk will be tested to obtain the physical and mechanical properties of this species. After the tree samples were sawn to $40 \operatorname{logs}$ formed, it is collected at one side so it would be easier to 
lift the tree logs onto a truck. The method that has been used to move logs from where they were cut to a truck is as shown in Figure 2.
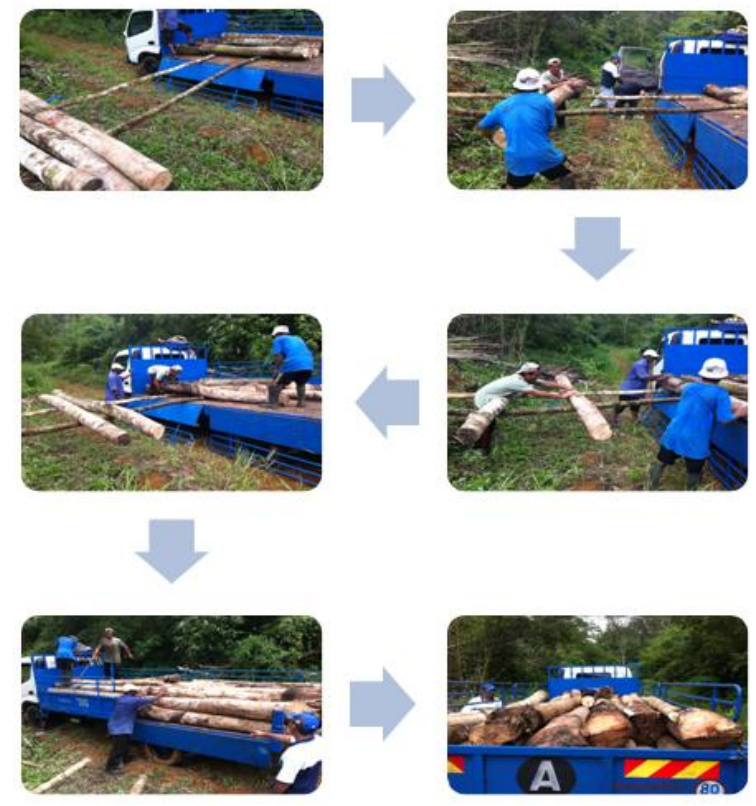

Fig. 2 The picture in the flow chart shows method that has been used to move logs

To perform the laboratory work, the sampling of specimens was made from bottom to top portion of the tree logs. The log was ripped into half through the pith to obtain the flitches. Next, the flitches undergo the machining process. The flitches were subsequently ripped across the diameter and converted to the sample size of 50 x $100 \times 2000 \mathrm{~mm}$ for NDT MOE Evaluator test as shown in Figure 3. The small specimens from each sample are taken to test its moisture content and basic density. (Refer Figure 4)

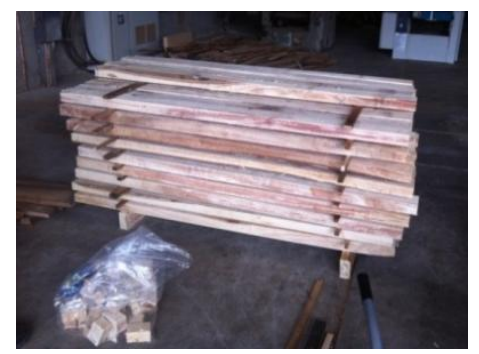

Fig. 3 a total of 78 sample size of $50 \times 100 \times 2000 \mathrm{~mm}$ is obtained

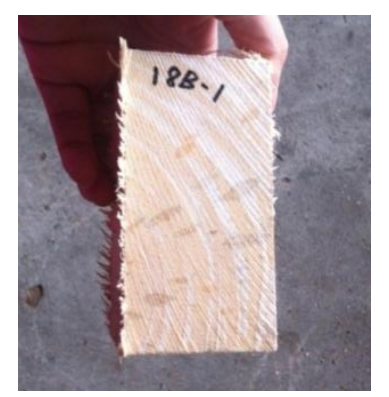

Fig. 4 Small sample from each specimen is taken to test the moisture content and basic density
B. Testing Methods - Mechanical Strength Properties

The NDT MOE Evaluator test is conducted to obtain the modulus of elasticity (MOE) of the samples. To perform the test, the samples shall be supported at both ends. The height of the support is at about waist height to facilitate the hammering while watching the monitor at a comfortable level. The PXI and monitor are placed near to one end of the specimen where the microphone is placed. Before conducting the test, the microphone is connected to the microphone stand and the electret is faced towards one end of the specimens. The axis of the microphone should lie on the same axis of the specimen as well as the direction of the sound wave produced by the hammering. Then, the hammer is hit on the opposite end of the samples as shown in Figure 5. The results of the MOE, Natural Frequency and Density together with the specimen parameter will be automatically recorded every time the hammer was hit on the specimen.

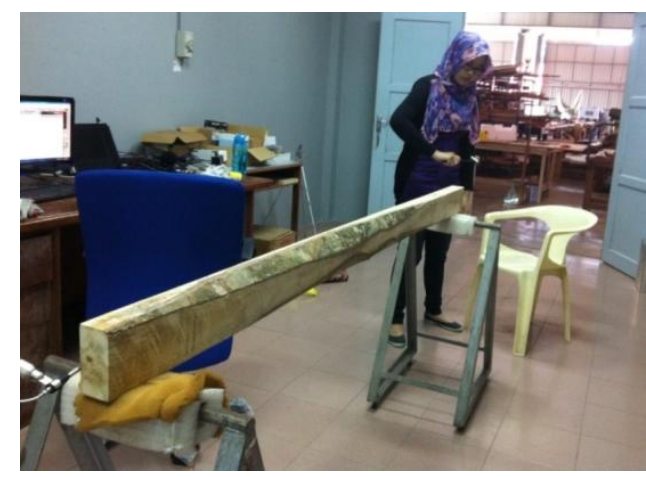

Fig. 5 Hitting the sample with a hammer to obtain the data.

C. Testing Methods - Physical Properties

- Moisture content determination

The moisture content test is carried out after each small specimen is obtained from each structure size samples. The specimens are weighed and were oven-dried at $103 \pm 2^{\circ} \mathrm{C}$ until a constant weight was obtained. Then, the oven-dried weights were taken to determine the moisture content by using the formula:

Moisture content $(\%)=\frac{\mathrm{W} 1-\mathrm{W} 0}{\mathrm{~W} 0} \times 100$

Where, W1 = Weight of specimen after the test $(\mathrm{g})$

$\mathrm{W}_{0}=$ Oven-dry weight $(\mathrm{g})$

\section{- $\quad$ Basic Density determination}

The test specimens shall be weighed, and the dimensions of the green samples were taken before they were placed into the oven to find out the green volumes. Then, the specimens were dried in an oven at 105 degrees centigrade until a constant weight is achieved. The basic density was determined by the using formula:

$$
\text { Basic Density }\left(\mathrm{g} / \mathrm{cm}^{3}\right)=\frac{\mathrm{w} 0}{\mathrm{Vg}}
$$

Where, $\mathrm{V}_{\mathrm{g}}=$ Volume at green condition $\left(\mathrm{cm}^{3}\right)$

$$
\mathrm{W}_{0}=\text { Oven-dry weight }(\mathrm{g})
$$

\section{III.RESULTS AND DISCUSSION}

The test result of modulus of elasticity, basic density and moisture content of structural size specimens of Hevea brasiliensis is shown in Table 1. A total of 40 samples in 
green condition and 38 samples in air-dry condition were tested.

TABLE I AVERAGE VALUE OF MOE, DENSITY AND MOISTURE CONTENT

\begin{tabular}{|c|c|c|c|c|}
\hline \multirow{2}{*}{ Condition } & \multicolumn{2}{|c|}{ Top } & \multicolumn{2}{c|}{ Bottom } \\
\cline { 2 - 5 } & Green & $\begin{array}{c}\text { Air- } \\
\text { Dry }\end{array}$ & Green & $\begin{array}{c}\text { Air- } \\
\text { Dry }\end{array}$ \\
\hline $\begin{array}{c}\text { MOE } \\
\left(\mathbf{N} / \mathbf{m m}^{2}\right)\end{array}$ & $\begin{array}{c}15133 . \\
55\end{array}$ & $\begin{array}{c}15552 . \\
69\end{array}$ & $\begin{array}{c}13709 . \\
94\end{array}$ & $\begin{array}{c}13930 . \\
70\end{array}$ \\
\hline $\begin{array}{c}\text { Density } \\
\left.\text { (kg/m }^{\mathbf{3}}\right)\end{array}$ & 795.60 & 659.10 & 825.70 & 756.60 \\
\hline $\begin{array}{c}\text { MC } \\
(\%)\end{array}$ & 55.02 & 18.00 & 55.41 & 18.00 \\
\hline
\end{tabular}

The results from Table 4.1 have been converted into percentage for ease comparison, and it is plotted in a bar chart as shown in Figure 6.

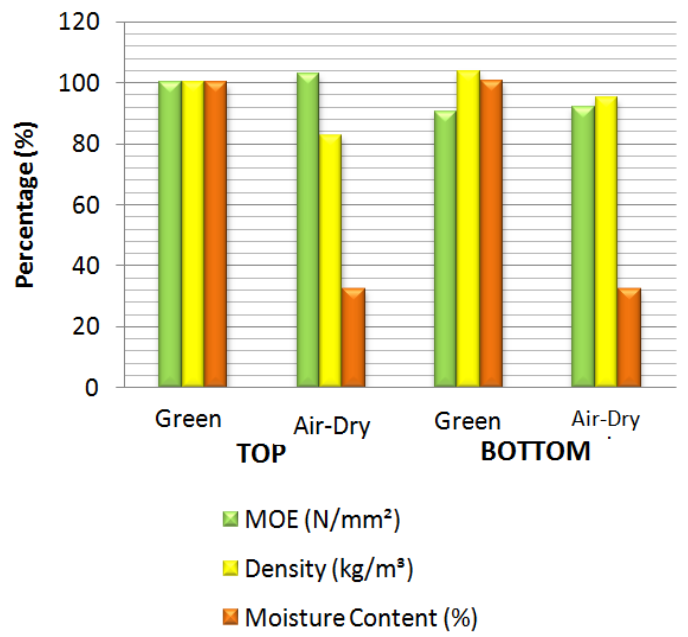

Fig. 6 Percentage of samples in green and air-dry condition

Based on both Figures shown, Modulus of Elasticity (MOE) is higher in air-dry condition for top and bottom part when compared to green condition. However the increment of MOE for top part is higher than the bottom part. MOE for the top part increase about $419.14 \mathrm{~N} / \mathrm{mm}^{2}$, while MOE for the bottom part increase about $220.76 \mathrm{~N} / \mathrm{mm}^{2}$. The reason why such event happened is because wood is considered as cellular composition. Different species or same species from different timber gave different physical and mechanical properties. Wood is described as a heterogeneous, hygroscopic, cellular and anisotropic material [10]. That means it is made up of a diverse range of different items, it attracts water molecules from the existing environment though absorption or adsorption, it has a cellular structure and its properties are directionally dependent.

The density for top and bottom part of Hevea brasiliensis is decreased about $17.16 \%$ and $8.68 \%$ respectively when put to air-dry. However, there is an increment of $3.78 \%$ for density at green condition between the top and bottom part of Hevea brasiliensis. The density between top and bottom part of Hevea brasiliensis in air-dry condition also increase about $12.26 \%$. This finding is similar to the research [21] where timbers at the bottom tree bole section are slightly denser than the top tree bole section. Furthermore, density is an excellent indicator of wood strength, the higher the density the stronger the wood. The overall mean for density in air-dried condition for top and bottom part of this timber species are $660 \mathrm{~kg} / \mathrm{m}^{3}$ and $760 \mathrm{~kg} / \mathrm{m}^{3}$ respectively. Thus, Hevea brasiliensis is classified under light hardwood [7].

Based on this research, by comparing the amount of defects of the samples from low to high MOE value, we can see an irregular defect particularly knots and wane at both flatwise and edgewise orientations of the samples. It is impossible to use defect free samples in this research since the structural size sample is bigger than the small clear sample. Even samples that have high MOE value have the severe defect. This is because most of the defects are waney edge which is caused by conversion during sampling process. Wane usually only affects the appearance, but not the strength of the wood. For samples with low MOE value, most of the defects are knot. Knot in the sample for this research can be seen with the naked eye where a hard cross grain mass of wood is formed in the specimen where a branch grows. They can weaken the timber or disfigure the surface where this defect causes the low MOE value. This also agreed by [4], where the occurrence of defects such as knots, sloping grain and inherent properties might reduce the strength value of timber. Therefore, this can be conclude that, the timber defect affect the results obtained for NDT MOE Evaluator test where the strength of sample that has only knots are more affected than the sample has only wane.

\section{IV.CONCLUSION}

Hevea brasiliensis is classified under light hardwood. Hevea brasiliensis in air-dry condition have higher strength with overall mean value of $14237.03 \mathrm{~N} / \mathrm{mm}^{2}$ for MOE compared to Hevea brasiliensis in green condition with MOE value of $14208.21 \mathrm{~N} / \mathrm{mm}^{2}$. This means moisture content affect the strength properties of the timber. Based on Malaysian Standard 3.44:1978, Hevea brasiliensis falls under the strength group B in timber grading. Based on Malaysian Timber Industry, Hevea brasiliensis is under strength group 5. Thus, when treated properly, Hevea brasiliensis may be recommended for structural applications such as formwork, battens in roofing, as a floor boarding and parquetry and many more.

\section{ACKNOWLEDGEMENT}

The authors would like to gratefully acknowledge everyone involve in this research especially to family, Dr. Gaddafi Ismaili, and also the staff of Mechanical Testing Section particularly Dr. Alik Duju, Laboratory Assistant Nungah Liang for their guidance and support.

\section{REFERENCES}

[1] Alik Duju \& Badorul Hisham Abu Bakar, (2002), Strength Performance of Full-Size Structural Timber of Dryobalanops Species of Sarawak, Sarawak Forestry Corporation, Kota Sentosa, Kuching, Sarawak, Malaysia. 
[2] British Standard Institution, 1979, BS 5820:1979, Methods of Test for determination of certain physical and mechanical properties of timber in structural size, 2 Park Street London W1A 2BS.

[3] Forest Research Institute of Malaysia (FRIM), 2011, NDT MOE EVALUATOR, Dr. Omar Khaidzir, Kepong, Selangor, Malaysia.

[4] Gaddafi, I., Badorul, H.A.B.,\& Khairul Khuzaimah, A.R. (2011). Evaluation of Acacia mangium in structural size at green condition. UNIMAS e-Journal of Engineering, 2, 1-6.

[5] Green, D. W., Winandy, J. E., \& Kretschmann, D. E. (1999). Mechanical Properties of Wood. In Wood as an engineering material (p. 463). Madison, WI : US: Department of Agriculture, Forest Service, Forest Products Laboratory.

[6] Hong L.T. \& Sim H.C. Eds. 1994. Rubberwood - Processing and Utilization. Malayan Forest Records No. 39, Forest Research Institute Malaysia, $249 \mathrm{pp}$

[7] Husin, Marini H., Pek, \& Yaw Kee, (2002), Characteristic and Strength Properties of Structural Hardwood Plywood Produced in Sarawak, paper presented at the TRTTC/STA Forest Product Seminars Seminar 21-22 November 2002, Kuching, Sarawak, Malaysia.

[8] Itto, C. F. C., \& Rev, P. D. (2007). Rubberwood Processing Manual, 4(I)

[9] Jim L.Bowyer, Rubin Shmulsky, \& John G. Haygreen, 2007, Forest Products \& Wood Science, $5^{\text {th }}$ Edition, Blackwell Publishing, USA.

[10] John Leckie (2007), Innovative Connections Steel and Timber, University of Waterloo. Retrieved October 28, 2015, from: http://www.tboake.com/SSEF1/timber.shtml

[11] Leonardo da Vinci Pilot Project, (2008). Handbook 1 - Timber Structures, Educational Materials for Designing and Testing of Timber Structures (TEMTIS), Europe.

[12] Malaysian Rubber Board, (2013). The Malaysian Natural Rubber Industry. $\quad$ Retrieved November 2, 2015 from:http://www.lgm.gov.my/LeftImpactBlowUpEN.htm.

[13] Naohiro Kuroda \& Ling Wang Choon, (1996), Measurements of Moisture in Wood, paper presented at the TRTTC/STA, Forest Products Seminar '96', 11-13 March 1996, Kuching, Sarawak , Malaysia.

[14] Rashid, A., \& Ehsan, S. D. (2011). Properties and Performance of Rubberwood Particleboard Treated With Bp ® Fire Retardant, 3(2), $1-8$

[15] Simpson, W., \& Tenwolde, A. (1999). Physical Properties and Moisture Relations of Wood. In Wood as an engineering material (p. 463). Madison, WI: US: Department of Agriculture, Forest Service, Forest Products Laboratory.

[16] Timber Bridge Maintenance Manual, February 2005, Appendix DNon-Destructive Testing, Department of Main Roads, Queensland Government.

[17] Yamsauensung, R., \& Buaphud, K., (2006), Effects of superheat steam on the drying of rubberwood, Prince of Songkla University, Hat Yai, Songkhla, Thailand.

[18] Yongdong, Z., Mingliang, J., Ruiqing, G., \& Xiaoling, L. (2007). Rubberwood Processing Manual, Research Institute of Wood Industry, Chinese Academy of Forestry, Beijing.

[19] Zziwa, A., Mugambwa, R., Kizito, S., Sseremba, O.E., \& Syafuna A. (2012). Basic Density, modulus elasticity and modulus of rupture o Artocarpus heterophyllus. Uganda Journal of Agricultural Sciences, 2012, 13(1): 12-23.

[20] Shaw, R. (2010, November 27). Rubber Plantation In Malaysia. Retrieved November 2, 2015, from http://www.scribd.com/doc/44125674/Rubber-Plantation-InMalaysia\#scribd

[21] Gaddafi, I., Badorul, H.A.B.,\& Khairul Khuzaimah, A.R. (2011). The Behavior of Strength Properties from Three Different Tree Boles of Aras in Sarawak. UNIMAS e-Journal of Engineering, 2, $1-5$. 